\title{
TRADITIONS IN JAPANESE CORPORATE CULTURE AND ITS IMPACT ON WORK PERFORMANCE
}

\author{
Kurtz LAW ( $^{*}$, Irina TARABAN ${ }^{b}$, Takatomo ITOI ${ }^{c}$, Dorin MARCHIS $^{d}$, Saddam IQBAL $^{e}$ \\ a,b,c,d,Bucharest University of Economic Studies, Romania \\ ${ }^{e}$ Babes Bolyai University, Romania
}

\begin{abstract}
This paper examines core cultural differences between Western and Japanese employees' perceptions of the sense of belonging, morale, team conflict and work devotion in the context of work productivity. A questionnaire-based survey involving 135 employees from organizations in Japan, was carried out for data collection. The main results obtained through structural equation modelling suggest a positive effect on work productivity between three of the elements, morale, conflict and work devotion, and a negative correlation for the sense of belonging. The findings may be useful for cross-cultural understanding when undertaking business projects with Japanese companies and employees.
\end{abstract}

KEYWORDS: belonging, corporate culture, morale, worker productivity, team conflict

DOI: 10.24818/IMC/2021/04.06

\section{INTRODUCTION}

Despite the huge impact that the COVID-19 pandemic has had on nations' economies, Japan's economic condition has shown itself to be relatively robust. Japan's GDP has recently been reported at $-4.8 \%$, but as of 2019 had experienced a consistent annual growth of $0.27 \%$ (O'Neill, 2021; Ministry of Foreign Affairs, 2021). A quarterly real growth rate of $2.8 \%$ was stated by the Ministry of Foreign Affairs in 2021 and a Reuter's poll forecasted an annualized growth of $1.6 \%$ (Ministry of Foreign Affairs, 2021; Komiya, 2021). These forecasts suggest that Japan is already experiencing a gradual economic recovery.

The Japanese Ministry of Economy, Trade and Industry (METI) (2019) estimate that 68.8\% of Japan's total workforce are employed in Small and Medium Enterprises (SME). Additionally, METI reported that SMEs employ between 50-300 workers depending on industry. The ratio of which are $3.45 \%$ for agriculture, forestry and fisheries, $23.5 \%$ for mining, construction and manufacturing and $71 \%$ for all other mainstream industries such as medical health care, wholesale and retail trade, services and so on (Ministry of Internal Affairs and Communications, 2018).

The researchers hypothesize that core Japanese cultural principles have supported work performance despite ongoing hardships. These are not only limited to the coronavirus pandemic, but also socio-economic factors such as decreasing population, ageing society and associated problems such as insecurities over future pension stability.

This research aims to identify work productivity efficiency variables of belonging, morale, organizational conflict, and work as a duty, with fundamental core Japanese principles such as uchisoto for belonging, ikigai for morale, chinmoku, nemawashi and honne and tatemae relating to organizational conflict and kaizen with regards to work as a duty. Subsequently a statistical analysis

${ }^{*}$ Corresponding author. E-mail address: kurtz.law@man.ase.ro. 
is conducted to identify the correlation significance between them. These factors are investigated as impacting factors against worker productivity from the employee perspective in Japanese organizations.

\section{THEORETICAL FRAMEWORK \& HYPOTHESIS}

The sense of "belonging" in the West has been categorized by the ability to experience life in terms of satisfaction and occupational engagement (Hammell, 2014). Also, having a capability to experience a sense of proximity especially with others who share similar social or professional standing. It has been suggested that having a multi-layered network of friendships can enable interaction and connectedness with others in various social environments (Social Issues Research Center, 2007). Hammell further suggests that people desire to offer support and experience reciprocity. As a result, people can experience a sense of being valued as well as social inclusion. Team spirit in terms of shared interests can also contribute to a sense of shared social identity. Suzane (2012) further identifies that holding together in the face of adversity can heighten the sense of belonging.

In Japan, "belonging" can also be discussed with the relationship of rules of etiquette, and the importance of roles in terms of $u c h i$ and soto. Under this principle, it creates a clear distinction between ingroups known as "uchi" and outgroups known as "soto" (Ide, 1995). The word uchi refers to "home" such as family members, or personal networks and soto refers to the concept of "outside". Therefore, in business, an employee's organization would be considered uchi and a customer would be soto. However, perception changes depending on scenario. For example, in one instance, a manager might consider other managers to be $u c h i$ and subordinates might be considered soto. But, in a different instance, the same manager might consider his subordinates to be his team, therefore uchi and managers in other departments to be soto (Barton, 2017).

The principle has a further significance in spoken language. For example, when speaking with people from the outgroup, people who are soto must be honored, and people from the ingroup need to be humbled. Linguistic level of formality and politeness in vocabulary are adopted to suit the appropriate scenario. This effect connects to expectations on how a person feels they should be treated, so as to not create offense.

Murugavel and Somaraju (2016) identified that conflict is often caused by cross-cultural differences. For example, in the West, the focus tends to be placed on compromise and collaboration. Consequently, an inability to predict individuals' conflict styles or their capability to conform to host country norms can lead to conflict. Isa (2015) further supports this view, stating that employees' personalities and values exacerbated by poor communication can increase organizational conflict. Isa further suggests that gossip has a strong impact on spreading inaccurate information or assumptions compounding negative sentiment, potentially prolonging the state of conflict as employees feel slighted or inconvenienced. Conflict can also occur when there is a perception of unfairness, stress or harassment. For example, stress by overwork, financial issues and family issues can potentially trigger passive-aggression or explosive self-expression (Bodenmann \& Meuwly, 2010; Leka \& Jain, 2010).

Hatvany and Pucik (1981) identified that Japanese business culture places a strong emphasis on organizational unity than individual identity. Group consensus is often more important than individual opinion. This tends to occur, regardless of the individual opinion's merit and it has been suggested that this is partly explained by the Japanese tendency to have interdependent personalities (Ito, et al., 2018; Ide, 2012). This begins from the engagement of new employees and an intensive socialization as they are assimilated into the existing corporate culture. Tang, et al. (1999) further states that the Japanese prefer several core principles such as; trusting employees, building employee loyalty, recognizing employee accomplishments and employing consensual decision making. 
While within ingroups, honesty or honne is socially acceptable, however when dealing with outgroups, Japanese may employ the concept of tatemae which results in refraining from saying what is believed where it is likely to cause disharmony.

The definition of "morale" in Western context is not clearly defined. However, employee morale is often associated with job satisfaction, feelings of well-being and an emotional connection with their workplace environment (Sabitova, et al., 2020; Mallik, et al., 2019; Bhasin, 2018; McKnight, et al. 2001). Furthermore, it is suggested that management and policies such as affecting employee communications or providing support, and risk such as the potential for downsizing, have high impact on factors influencing positive or negative employee morale (Behm, 2009; Kettley, 1995).

The Japanese principle of ikigai can be associated with morale, and may be derived from iki, meaning "life" and gai meaning "benefit." Combined, it can therefore be interpreted to mean, "a reason for living" (Hasegawa, et al., 2003). Nakanishi (1999) identifies ikigai as an important factor for Japanese to achieve a better health or fulfilling life and Tanno, et al., (2008) further states that through a life worth living, can contribute to a sense of well-being, pleasure and self-realization. Interestingly, Kumano (2018) suggests that ikigai relies upon an internal commitment devoid of exterior coercion.

"Work devotion" in the West seems to have an associated stigma such as relating to "working too much" or an inability to separate work-life from non-work-life. Kodz, et al., (2003) suggests that these aspects contribute to physical and mental health issues, decreased productivity and lower morale. Low (2018) infers that many employees work to meet fundamental needs as might be described through Maslow's Hierarchy of Needs in figure 1. Therefore, working may lead to basic financial necessities such as buying food, paying rent or debt. Additionally, offering job security to promote family stability, achieving professional standing to fulfil social acceptance, overcoming work challenges to gain prestige and self-esteem, and through achieving full potential, enable the sense of self-actualization (McLeod, 2018).

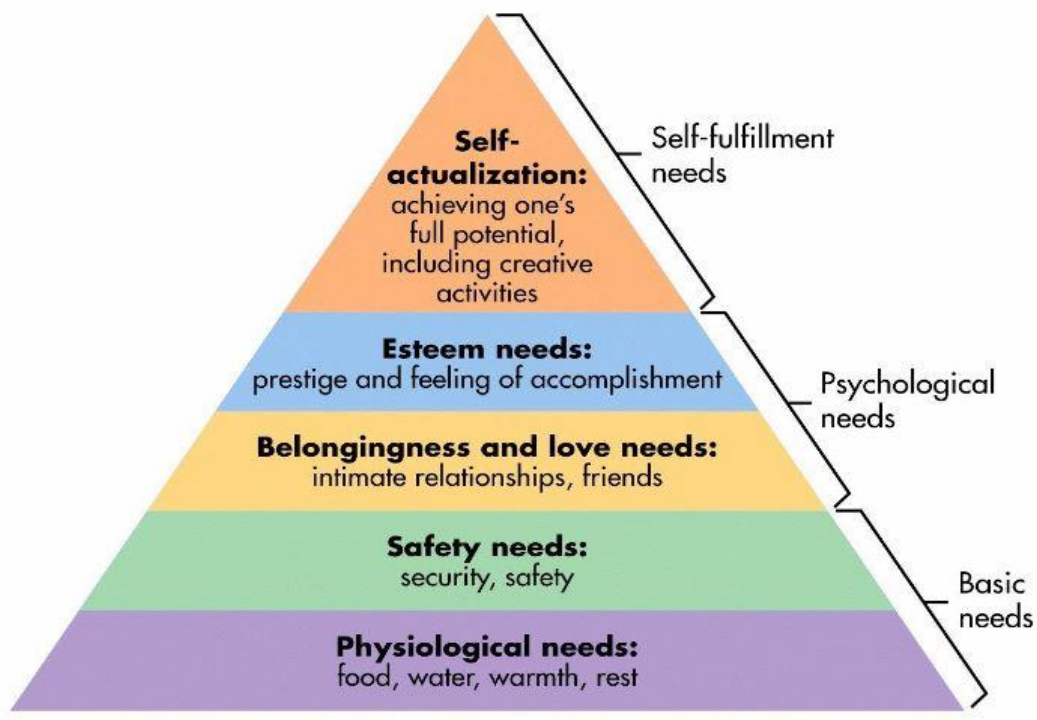

Figure 1. Maslow's Hierarchy of Needs.

Source: McLeod (2018)

The Japanese however seem to have a higher tolerance and acceptance for longer working hours as well as irregular work schedules (Kuroda \& Yamamoto, 2012). During the Kuroda and Yamamoto study, they determined that average weekly hours ranged between 49 to 53 hours per week. While by law, standard worktime is 40 hours per week, with a maximum of 48 hours including overtime. However, Article 41, number 2 of the Japan's Labor Standards Act allow employers discretionary 
powers to make assumptions on number of hours worked regardless of actual hours worked. Recruiting fresh graduates and training them to fit the existing corporate culture encourages workers to believe that working long hours, job rotation or seniority wages is the norm (Ono, 2018). Additionally, concepts such as kaizen which promote continuous improvement and incremental self-learning can drive Japanese employees to work beyond individual needs such as remuneration, or free time (Rahmanian and Rahmatinejad, 2013).

\section{RESEARCH OBJECTIVES}

This research investigates the results of a survey held in 2021 of Japanese employees on how they perceive the current state of Japanese corporate culture and environment on their individual work productivity. A focus group was later held to discuss reasons for their answers and a statistical analysis was conducted to explain and validate the findings.

The primary research question for this study was: Is there a significant correlation between worker productivity efficiency variables of belonging, team conflict, morale and work devotion and work productivity in organizations in Japan?

\section{RESEARCH METHODOLOGY}

In order to realize the objective of our study, we used information collected from employees in Japanese organizations. This research utilized the results of a survey with a sample size of 135 respondents as of September 2021. Considering a $90 \%$ confidence factor with a maximum population of 33,601,000 and a 7\% margin error, this sample size was considered to have a high likelihood of statistical accuracy.

The survey was carried out over a 6-month period from March 2021 and participants submitted their surveys anonymously online through Surveymonkey.com. The age of respondents was between $30-65$, with a gender mix of $57 \%$ male, $43 \%$ female. $89 \%$ of respondents were native Japanese and the remaining $11 \%$ were from non-Japanese nationalities. Employees in Japanese organizations were asked to perceived factors such as belonging, team conflict, morale and work devotion on their individual productivity. A voluntary focus group was held with 6 members who discussed the reasons for the answers that they had given during the survey and statistical analysis was conducted using SPSS Statistical package, version 28.0 (IBM, 2021a) and SPSS AMOS (IBM, 2021b).

Our research focuses on 4 main questions:

1. How much impact does a feeling of high team morale impact workers' productivity?

2. How much impact does the feeling of belonging in one's team and company impact workers' productivity?

3. How much impact does an expectation of overtime work as a duty have on workers' productivity?

4. How much impact does team conflict have on workers' productivity?

The answers were given using the Likert scale, where 5 indicated highest impact, 1 indicated least impact and an optional NA was offered for: I cannot or do not want to answer.

\section{FINDINGS AND DISCUSSION}

The results of the survey showed that 22 of the 135 respondents decided not to answer the question regarding whether belonging impacted their worker productivity. In addition, the mean average was 3.62 indicating a relatively ambivalent yet positive perception by Japanese workers that the sense of belonging was significant to their performance. In a focus group with 6 of the respondents, it was suggested that some respondents may have felt embarrassed or shame, that either their company did 
not promote an environment of belonging, or that the employee themselves would feel a sense of failure or responsibility to be unable to achieve compatibility with their company, team or peers. This may in part explain why they chose not to answer.

On the other hand, the impact of higher morale was perceived to be primarily positive with a mean average of 4.19 indicating that employees who experience high morale, have higher productivity. Conversely, the awareness of team conflict showed a mean average of 1.97, indicating that employees felt that team conflict contributed negatively to their work productivity. Finally, work devotion was interpreted by expectation of overtime, whether paid or unpaid. The data reflects negative work performance as employees who anticipate overtime indicated that their productivity declined.

A structural equation model was constructed to determine the correlation between the four, work productivity impacting variables as shown in Figure 2.

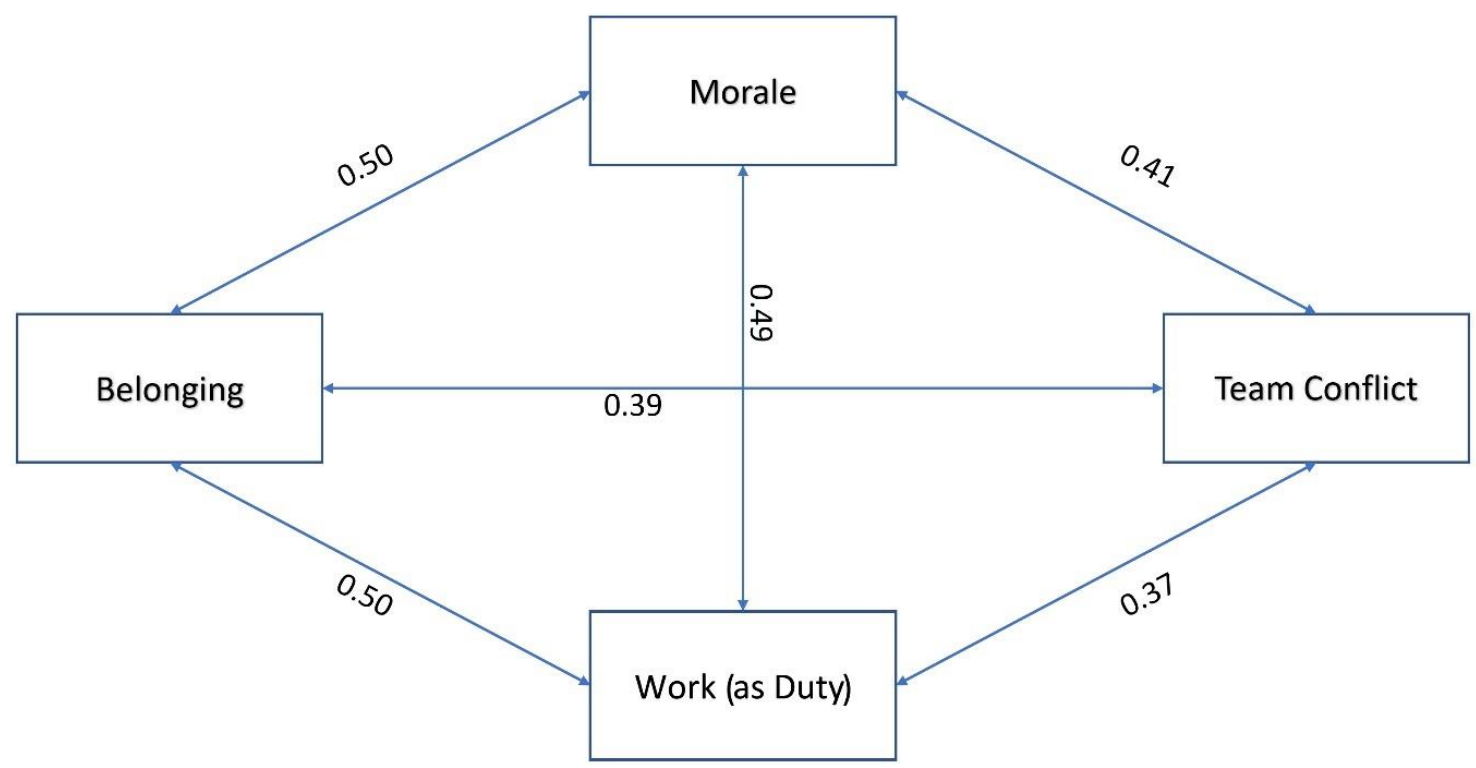

Figure 2. Correlation model between 4 factors impacting worker productivity Source: own representation of the data using SPSS AMOS Version 28 (IBM, 2021b).

Each variable showed a significant correlation with each other ranging between 0.37 to 0.5 , with a $\mathrm{p}$ $<0.001$. With regards to the impact on worker productivity, the empirical results suggest that Work (as Duty) has a significant impact $(\beta=0.882 . \mathrm{p}<0.01)$, Team Conflict has less impact $(\beta=0.182, \mathrm{p}$ $<0.283)$, Morale has a moderate impact $(\beta=0.360, \mathrm{p}<0.071)$. However, the unexpected outcome for the sense of belonging suggests a negative impact $(\beta=-0.349, p<0.057)$. Further examination of this figure will be undertaken in the future to verify its validity.

Table 1. Coefficients ${ }^{\mathrm{a}}$

\begin{tabular}{|c|c|c|c|c|c|c|}
\hline \multirow{2}{*}{\multicolumn{2}{|c|}{ Model }} & \multicolumn{2}{|c|}{ Unstandardized Coefficients } & \multirow{2}{*}{$\begin{array}{c}\text { Standardized } \\
\text { Coefficients } \\
\text { Beta }\end{array}$} & \multirow[b]{2}{*}{$\mathrm{t}$} & \multirow[b]{2}{*}{ Sig. } \\
\hline & & $\mathrm{B}$ & Std. Error & & & \\
\hline \multirow[t]{5}{*}{1} & (Constant) & 1.771 & .564 & & 3.140 & .003 \\
\hline & Work (as Duty) & .882 & .231 & .517 & 3.818 & $<.001$ \\
\hline & Team Conflict & .182 & .169 & .119 & 1.083 & .283 \\
\hline & Morale & .360 & .196 & .264 & 1.832 & .071 \\
\hline & Belonging & -.349 & .180 & -.163 & -1.939 & .057 \\
\hline
\end{tabular}

a. Dependent Variable: Worker Productivity

Source: own representation of the data using SPSS Statistics Version 28 (IBM, 2021a). 
The correlation analysis as shown in figure 2, of the four work productivity variables indicate that as the ratio of stronger sense of belonging to higher work productivity increases, the higher sense of morale to higher work productivity increases $\left(\mathrm{r}^{2}=0.50\right)$, the larger perception of work as a duty to lower worker productivity ensues $\left(r^{2}=0.50\right)$ and the higher sense of team conflict to lower worker productivity occurs $\left(\mathrm{r}^{2}=0.39\right)$. Additionally, as the ratio of impact between a stronger sense of work as duty to lower work productivity increases, a lower morale to lower productivity increases $\left(\mathrm{r}^{2}=0.49\right)$, and higher team conflict to lower work productivity also increases $\left(\mathrm{r}^{2}=0.37\right)$. Furthermore, as the ratio between a lower sense of belonging to lower work productivity increases, a higher sense of team conflict to lower worker productivity also increases $\left(r^{2}=0.39\right)$. And, as the ratio between higher sense of team conflict to lower worker productivity increases, the ratio of lower morale to less work productivity occurs $\left(\mathrm{r}^{2}=0.41\right)$.

\section{CONCLUSIONS}

In this article, we tried to contribute to the current knowledge of contributing factors to work performance by examining variables which impact worker productivity efficiency. Specifically, we examined Japanese employees' perceptions of belonging, morale, team conflict and work as a duty. For work as a duty, employees in Japanese organizations weighed the expectation of overtime as a duty against their work productivity. Since, our survey and focus group respondents were from Japan, we identified and discussed core Japanese philosophies which are a cornerstone for social and cultural interactions.

We utilized a survey as a quantitative research method, and attempted a correlation analysis using Structural Equation Modelling through SPSS. Additionally, qualitative research methods were used in the form of thematic coding to ascertain the worker productivity efficiency variables, and focus groups to further understand respondents reasons for answers given during the survey.

Limitations of this study include, time constraints as we would have liked to have gathered a larger sample size. Additionally, it would have been interesting to know what proportion of employees had been in a managerial role. From this, we could have examined whether perceptions of worker productivity changed based on a higher sense of duty, or a sense of responsibility.

\section{ACKNOWLEDGMENT}

This study was conducted as part of a doctoral program at the Bucharest University of Economic Studies and at Babes Bolyai University.

\section{REFERENCES}

Barton, D. W. (2017). Concept of Uchi-Soto: In-Groups and Out-Groups. Japanology. Arts and Culture. March 29, 2017. Available from: https://japanology.org/2017/03/concept-of-uchisoto-in-groups-and-out-groups/

Behm, M. (2009). Employee Morale. Examining the Link to Occupational Safety and Health. ASSE Foundation Research. Professional Safety. October 2009. Available from: https://www.researchgate.net/publication/241782969_Employee_Morale_Examining_the_Lin k_to_Occupational_Safety_And_Health

Bhasin, H. (2018). Employee Satisfaction and Morale among Skilled Workforce of a Steel Manufacturing Plant. Journal of Organization \& Human Behavior, 7(4), 31-42.

Bodenmann, G., \& Meuwly, N. (2010). Stress, anger, and verbal aggression in intimate relationships: Moderating effects of individual and dyadic coping. Journal of Social and Personal Relationships, 27(3), 408-424. Available from: https://journals.sagepub.com/doi/ pdf $/ 10.1177 / 0265407510361616$ 
Hammell, K.W. (2014). Belonging, Occupation, and Human Well-Being: An Exploration. Canadian Journal of Occupational Therapy, 8(1), 39-50. Available from: https://doi.org/10.1177\%2F0008417413520489

Hasegawa, A., Fujiwara, Y., Hoshi, T., \& Shinkai, S. (2003). Regional Differences in Ikigai (Reasons(s) for Living) in Elderly People, Relationship between Ikigai and Family Structure, Physiological Situation and Functional Capacity. Nihon Ronen Igakkai. 40(4), 390-396. Available from: https://pubmed.ncbi.nlm.nih.gov/12934571

Hatvany, N., \& Pucik, V. (1981). An Integrated Management System: Lessons from the Japanese Experience. Academy of Management Review, 6(3), 469-480. Available from: https://www.researchgate.net/publication/271775943_An_Integrated_Manage ment_System_Lessons_From_the_Japanese_Experience

IBM. (2021a). IBM SPSS Statistics. Version 28. Available from: https://www.ibm.com/uken/products/spss-statistics

IBM. (2021b). IBM SPSS AMOS. Version 28. Available from: https://www.ibm.com/uken/products/structural-equation-modeling-sem

Ide, S. (1995). Kokusaika Shakai ni Okeru Gengo to Bunkato Aidentiti [Language, Culture and Identity in Internationalized Society]. Kokusaika to Nihongo ka [Globalization and Japanesation]. Tokyo. Monkasho.

Ide, S. (2012). Roots of Wakimae Aspect of Japanese Politeness: Modal Expressions and Japanese Sense of Self. In M. Meeuwis \& J. Ostman, (Eds.), Pragmaticizing Understanding, 121-138. Amsterdam: John Benjamins.

Ito, A., Gobel, M. S., \& Uchida, Y. (2018). Leaders in Interdependent Contexts Suppress Nonverbal Assertiveness: A Multilevel Analysis of Japanese University Club Leaders' and Members' Rank Signaling. Frontiers in Psychology. May 2018. 9. Article 723. Available from: https://bura.brunel.ac.uk/bitstream/2438/16315/1/Fulltext.pdf

Kettley, P. (1995). Employee Morale During Downsizing. The Institute for Employment Studies. Available from: https://www.employment-studies.co.uk/system/files/resources/files/291.pdf

Kodz, J., Davis, S., Lain, D., Strebler, M., Rick, J., Bates, P., Cummings, J., Meager, N., Anxo, D., Gineste, S., Trinczek, R., \& Pamer, S. (2003). Working Long Hours: A Review of the Evidence. Volume 1. Main Report. Employment Relations Research Series. No. 16. Available from: https://www.employment-studies.co.uk/system/files/resources/files/errs16_main.pdf

Komiya, K. (2021). Japan Seen Upgrading Q2 GDP on Stronger Business Spending. Reuters, Macro Matters. Retrieved September 21, 2021, from: https://www.reuters.com/world/asiapacific/japan-seen-upgrading-q2-gdp-stronger-business-spending-2021-09-03/

Kumano, M. (2018). On the Concept of Well-Being in Japan: Feeling Shiawase as Hedonic WellBeing and Feeling Ikigai as Eudaimonic Well Being. Applied Research in Quality of Life, 13(2-3), 419-433. Available from: https://ideas.repec.org/a/spr/ariqol/v13y2018i2d10.1007_ s11482-017-9532-9.html

Kuroda, S., \& Yamamoto, I. (2012). Impact of Overtime Regulations on Wages and Work Hours. Journal of the Japanese and International Economies. 26. 249-262.

Leka, S., \& Jain, A. (2010). Health Impact of Psychosocial Hazards at Work: An Overview. World Health Organization. Available from: https://www.researchgate.net/publication/337837445 _Health_Impact_of_Psychosocial_Hazards_at_Work_An_Overview

Low, A. (2018). Improving Workplace Productivity: Applications of Maslow's Need Theory and Locke's Goal Setting. Psychology and Psychological Research International Journal, 3(8), Available from: https://researchgate.net/publication/329732901_Improving_Workplace Productivity Applications of Maslow's Need Theory and Locke's Goal-Setting

Mallik, A., Mallik, L., \& Keerthi, D. S. (2019). Impact of Employee Morale on Organizational Success. International Journal of Recent Technology and Engineering, 8(4), November 2019. Available from: https://www.ijrte.org/wp-content/uploads/papers/v8i4/D8070118419.pdf 
McKnight, D. H., Ahmad, S., \& Schroeder, R. G. (2001). When Do Feedback, Incentive Control, and Autonomy Improve Morale? The Importance of Employee-Management Relationship Closeness. Journal of Managerial Issues, 13(4), Winter 2001.

McLeod, S. (2018). Maslow's Hierarchy of Needs. Simply Psychology. Available from: https://www.simplypsychology.org/maslow.html

Ministry of Economy, Trade and Industry. (2019). 2019 White Paper on Small and Medium Enterprises in Japan (Summary). Available from: https://www.chusho.meti.go.jp/ sme_english/whitepaper/whitepaper.html

Ministry of Foreign Affairs. (2021). Japanese Economy. MOFA. Available from: https://www.mofa.go.jp/policy/economy/japan/index.html

Nakanishi, N. (1999). "Ikigai" in Older Japanese People. Age and Ageing, 28. 323-324. Available from: https://academic.oup.com/ageing/article/28/3/323/31016

Omi, Y. (2012). Collectivistic Individualism: Transcending a Traditional Opposition. Culture \& Psychology. 18(3), 403-416. Available from: https://doi.org/10.1177/1354067X12446232

Ono, H. (2018). Why Do the Japanese Work Long Hours? Japan Institute for Labor Policy and Training. Available from: https://www.jil.go.jp/english/jli/documents/2018/005-03.pdf

O’Neill. (2021). Japan: Real Gross Domestic Product (GDP) Growth Rate from 2016 to 2026. Statista. Retrieved: September 21, 2021, from: https://www.statista.com/statistics/ 263607/gross-domestic-product-gdp-growth-rate-in-japan/

Ozawa, M. (2018). Co-Constructing Gender Binaries in a Japanese Interaction. Symposium about Language and 2019.262. Available from: http://salsa.ling.utexas.edu/proceedings/2018/Ozawa.pdf

Rahmanian, F., and Rahmatinejad, Z. (2013). Impact of Kaizen Implementation on Performance of Manufacturing Companies' Staff. European Online Journal of Natural and Social Sciences, 2(3), 1094-1103. Available from: https://core.ac.uk/download/pdf/230041772.pdf

Sabitova, A., Hickling, L. M., and Priebe, S. (2020). Job Morale: A Scoping Review of How the Concept Developed and is Used in Healthcare Research. BMC Public Health. Vol.20(1166). Available from: https://bmcpublichealth.biomedcentral.com/articles/10.1186/s12889-02009256-6

Tang, T. L. P., Kim, J. K., and O’Donald, D. A. (1999). Perceptions of Japanese Organizational Culture. Journal of Managerial Psychology, 15(6), 535-559.

Tanno, K., Sakata, K., Ohsawa, M., Onoda, T., Yaegashi, Y., and Tamakoshi, A. (2008). Associations of Ikigai as a Positive Psychological Factor with all-Cause Mortality and CauseSpecific Mortality Among Middle-Aged and Elderly Japanese People: Findings from Japan Collaborative Cohort Study. Available from: https://doi.org/10.1016/j.jpsychores.2008.10.018

Taskiran, E., Cetin, C., Ozdemirci, A., Aksu, B., and Istoriti, M. (2017). The Effect of the Harmony between Organizational Culture and Values on Job Satisfaction. International Business Research, 10(5), Available from: https://ccsenet.org/journal/index.php/ibr/ article/download/66982/36827

Yilmaz, E., and Dilmac, B. (2011). An Investigation of Teachers Values and Job Satisfaction. Elementary Education Online, Vol 10(1). 302-310. Available from: https://citeseerx.ist.psu.edu/viewdoc/download?doi=10.1.1.668.9783\&rep=rep1\&type=pdf 